\title{
Roles and Student Identities in Online Large Course Forums: Implications for Practice
}

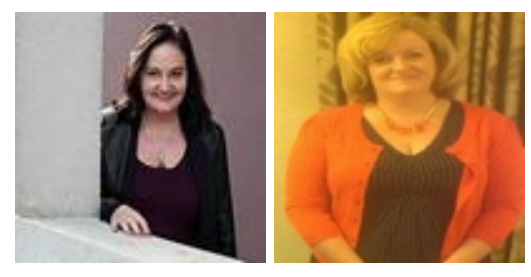

Jacqueline Aundree Baxter and Jo Haycock The Open University, UK

\section{Abstract}

The use of large online discussion forums within online and distance learning continues to grow. Recent innovations in online learning such as the MOOC (massive open online course) and concomitant growth in the use of online media for the delivery of courses in traditional campus based universities provide both opportunity and challenge for online tutors and learners alike. The recognition of the role that online tutors and student identity plays in the field of retention and progression of distance learners is also well documented in the field of distance learning. Focusing on a course forum linked to a single Level 2 undergraduate module and open to over 1,000 students, this ideographic case study, set in a large distance learning university, uses qualitative methodology to examine the extent to which participation in a large forum can be considered within community of practice (COP) frameworks and contributes to feelings of efficacy, student identity, and motivation. The paper draws on current theory pertaining to online communities and examines this in relation to the extent to which the forum adds to feelings of academic and social integration. The study concludes that although the large forum environment facilitates a certain degree of academic integration and identity there is evidence that it also presents a number of barriers producing negative effects on student motivation and online identity.

Keywords : Online forums; online identities; online learning; higher education; elearning 


\section{Background}

With $65 \%$ of its offering delivered online and 7,000 tutors supporting learning, the university offers 473 undergraduate modules, 60 continuous professional development modules, and 146 post-grad modules with $89 \%$ of students studying in order to further career aims. Since its inception in 1969 the university has taught over 1.8 million students using a blend of both online and face-to-face pedagogy. But a number of recent reports suggest that not only distance learning universities and their students stand to profit by new developments in online learning, but that traditional campus based universities can transform learning journeys by applying research into online pedagogies to turn to their advantage (OLTF, 2011): This is particularly important in light of the development of mass online open courses (MOOCs). This paper uses as its case a large online forum open to undergraduate students in order to study the ways in which engagement or non-engagement with the forum both aids and presents barriers to student motivation and feelings of agency. Agency has been found to be a key element in the formation of working and professional identities (see for example Baxter, 2012; Lave \& Wenger, 1991), and relates to feelings of being in control, on the part of the individual. This level of control has been found to be particularly important in the way in which it engenders feelings of positive motivation and links strongly to student retention and feelings of success (see Baxter, 2010, 2012). In drawing upon theory relating to online communities of practice (Hammond, 2000; Lave \& Wenger, 1991; Wenger, 1998) and online identity (Baxter, 2012, 2012a) it explores the ways in which a large online forum contributes to learners' sense of agency and identity.

\section{Context}

For some time now the use of online forums in distance learning has formed a substantial element of research into distance and online learning. Research has focused upon both practical approaches to online moderation as well as studies into the degree to which they can motivate and engage students in order to enhance their learning journey (see for example Cleveland-Innes \& Campbell, 2012; DeSanctis, Fayard, Roach, $\&$ Jiang, 2003). Some researchers suggest that the degree to which distance learners engage in online forums can be indicative of their capacity to progress within their studies, linking to both progression and retention (Baxter, 2012a; Baxter \& Martyn, 2010).

A number of researchers have investigated online forums as communities of practice, focusing on the ways in which they move their online learner participants from novice to expert status (Shea \& Bidjerano, 2009). Research into this function of online forums has become a leitmotif of studies in this area and the term has taken on nuanced meanings depending upon how and in what context it is used. Johnson's survey of current research on online communities of practice (2001) distinguishes between virtual communities as 'designed communities using current networked technology', making the distinction between these communities and communities of practice, which 'emerge within the designed communities via the ways their participants use the designed 
community' (p. 45). Work into the learning value of such communities has been investigated by a number of researchers: J ean Lave and Etienne Wenger (1991) termed it situated learning and focused on the constructivist nature of learning in this environment, identifying key elements of the environment as 'ill structured questions, learning in the social and physical context of real world problems, including group activities, collaboration and team work, shared and often negotiated goals' (p. 42). But Wenger's later work on the way in which participation within a community of practice forms and shapes identities sees identity in practice as neither self-reflective nor discursive (Lave \& Wenger, 1991, p. 151). A body of research within online communities disputes this, arguing that online identity in text based online communities is in many ways a discursive construction, formed from the way in which participants engage textually within the environment and reflect on the ways in which their posts reflect their online identities (see for example Garrison \& Cleveland-Innes, 2005; Hewitt \& Forte, 2006).

This area of research also reflects on the role of the online moderator (or tutor) in the creation of this online identity and the ways in which both cognitive and metacognitive strategies may be employed in order to foster engagement and participation whilst concomitantly strengthening the online identity through a deeper and more productive engagement with the environment (Garrison, 2007). Since then, both the role of the facilitator and the confidence and ability of the learner to participate in these forums have exercised many researchers; latterly in the context of massive open online courses (MOOCs), which rely upon large forums as a central part of their pedagogy (Anderson \& McGreal, 2012).

Investigation in online participation has more recently come to focus on the affective dimensions of integration, examining the role of emotions on motivation to participate (Angelaki \& Mavroidis, 2013). Angelaki and Mavroidis, in common with other researchers in this field, link emotions to the ability to create online social presence and remark that it is 'more significant to women rather than men, in particular, elements of 'the expression of emotions and non-verbal communication' (p. 90). Studies in this area have also identified the pivotal role played by metacognition in online learning: 'the ability of learners to take responsibility and control of the construction of meaning and confirmation of knowledge' (Akyol \& Garrison, 2011, p. 183). Raised levels of metacognition and, to a certain extent, motivation were also found in studies involving peer facilitation amongst students, such as the study carried out by Hew and Cheung (2008). Their research investigated the depth of threads in particular student to student interactions, and identified particular forms of Socratic questioning techniques and ways in which differing types of questions promoted deeper student to student interaction, as evidenced by more extensive threads (see for example Mazzolini \& Maddison, 2003), this then leading to heightened levels of confidence and enhanced participation. Henri's taxonomy of interaction identifies stages of participation in online forums (1992) (see Figure 1). This study takes a constructivist view of identity formation with learning and community integration as central to online student identity formation 
(Baxter, 2011; Lave \& Wenger, 1998). Figure 1 illustrates the ways in which the student moves from a relatively peripheral role in the community through to full integration. The increasing levels of learner confidence gained through this form of forum integration links positively to motivation, retention, and learner resilience (Burke \& Reitzes, 1981; Duemer et al., 2002). Although at first glance there seems to be little difference between the quasi-interactive and interactive elaborative stages, in terms of participation and learner integration into the forum, the step is significant. The quasiinteractive stage involves merely making reference to the contributions of others, without really using the information in order to build on the point. In contrast, during the interactive elaborative stage of participation, the student uses the points made by other students in order to either challenge or support. This has the effect of not only strengthening their argument, but also provides a cohesive element to the debate, rather than the list of disparate arguments and statements that often feature in the independent and quasi-interactive stages.

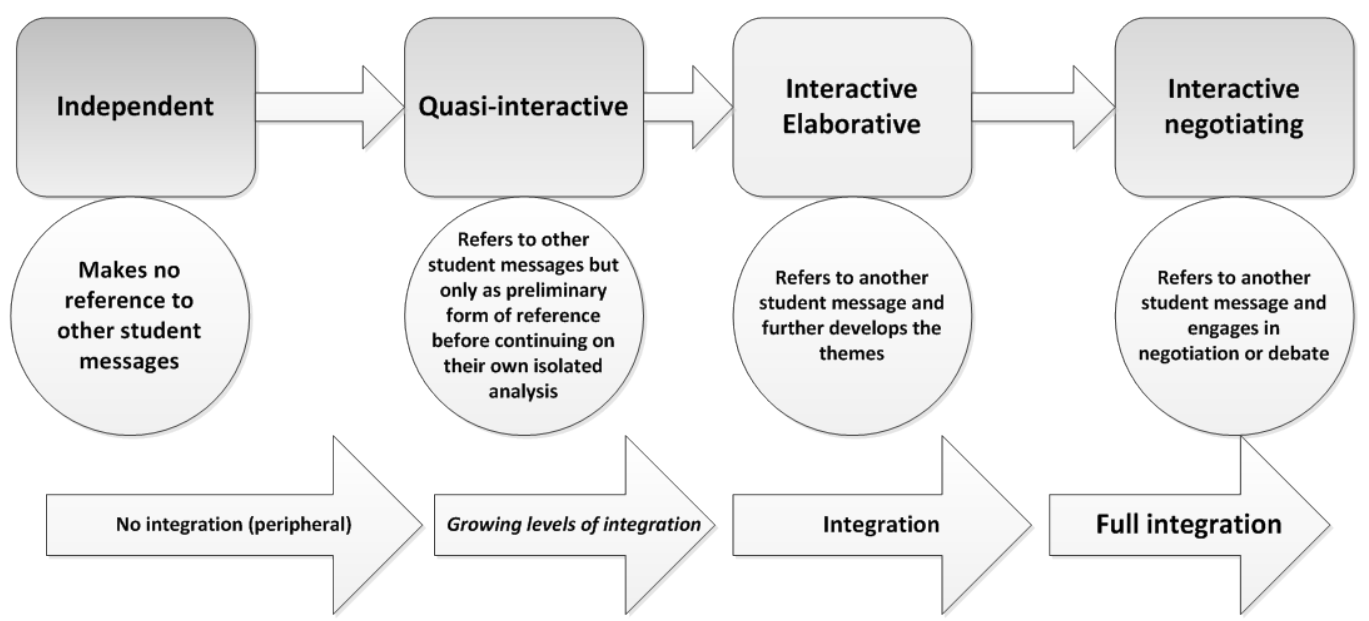

Figure 1. Henri's taxonomy of interaction (1992).

These extended discussions have been linked in other studies to the extent to which students feel agentive online, increasing their social presence and linking to motivation and efficacy (see for example Thomas, 2002).

\section{Identity and Community}

A number of studies have linked a strong and salient online identity to learner agency, resilience, and learner motivation to progress (see for example Baxter 2012a; Xie, DeBacker, \& Ferguson, 2006) and identified role and engagement with communities of practice as being a central element within this online identity, influencing both online behaviours and emotions.. The constructivist premise upon which online pedagogies are based, in common with humanist theories of learning, considers that working identities 
are constructed and used in order for individuals to make sense of their working environments (see for example J onassen, Davidson, Collins, Campbell, \& Haag, 1995). But to what extent do large online forums, now commonly used within both conventional distance offerings and MOOCs, contribute to a salient learner identity and what factors inhibit the development of this in the online context? The results from an early pilot focusing upon a large online forum open to over 2,000 students (Haycock, 2008) revealed that although over $50 \%$ of respondents stated a preference for large national forums compared to smaller forums based around individual tutor group, a substantial amount expressed concerns about the ways in which they portrayed themselves online (social presence). This concern extended to how this reflected upon both their identities as students and their ability to feel part of the forum. Research carried out in 2012 (Baxter, 2012a) reflected that these concerns often presented barriers to motivation and student progression. Both projects reflected a need for students to feel part of a community in order for them to feel authentic and agentive. This is also supported by work done elsewhere (see for example J ohnson, 2001).

Feelings of belonging to a community have been identified as being a core element in the construction of salient and robust working and student identities (see for example Caravallo J ohnson \& Watson, 2004). Figure 2 summarises elements identified within current literature on forums as online communities of practice which contribute and act as barriers to feelings of inclusion and motivation leading to strong learner identities.

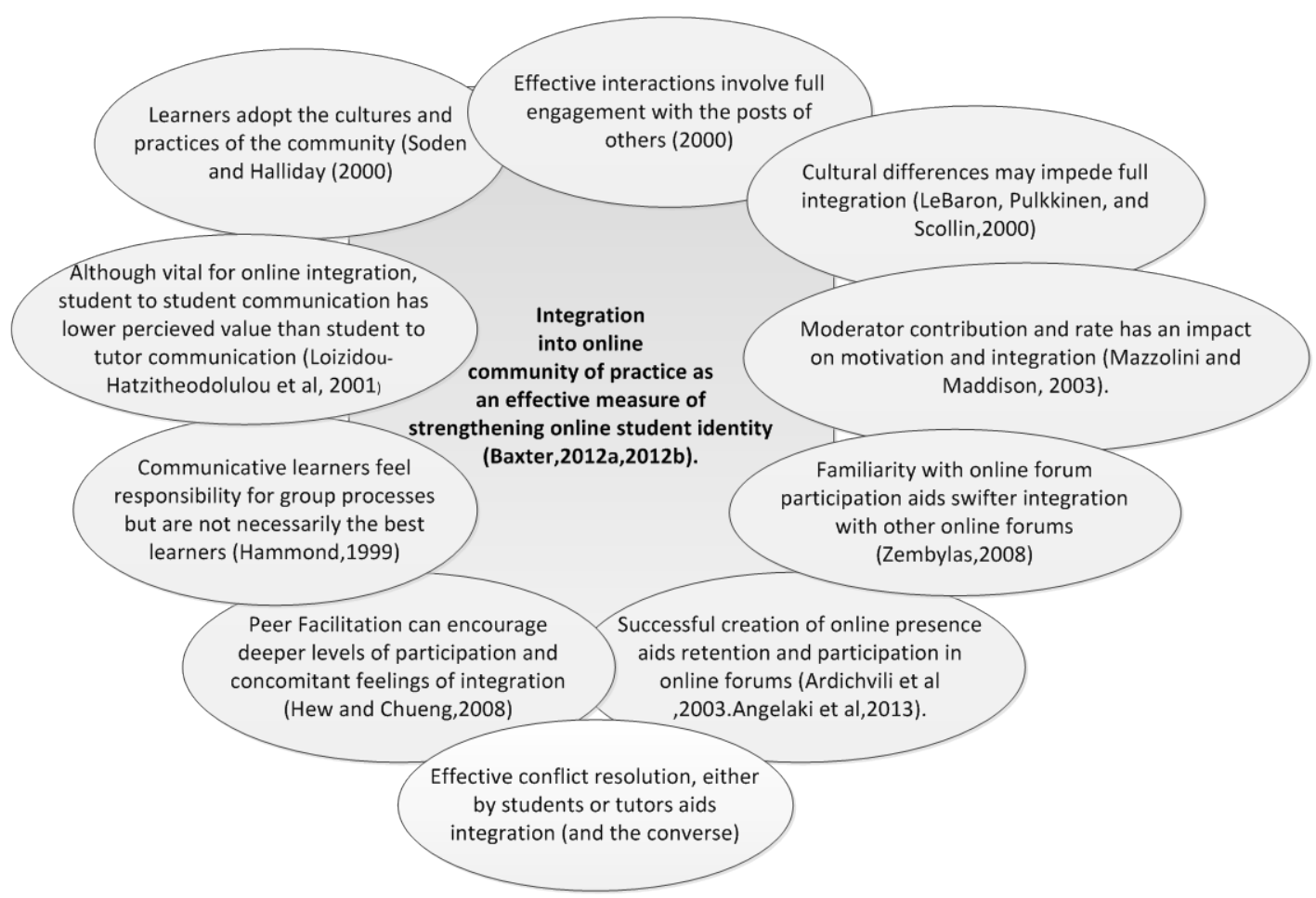

Figure 2. Key findings from current literature on forums. 
The diagram illustrates a number of elements relating to enhancement of learner identity and motivation in the specific context of online forum engagement. It reveals a complex mix of elements which have been found to influence the extent to which students engage and participate on forums. The illustration also highlights areas which may present difficulties and barriers to community integration and learner motivation; for example, if familiarity with the online forum aids swifter integration in other online forums, does this cause problems of combining those with little or no experience of this type of interaction in the case of those adept in the use of other forms of social networking?

This discussion has revealed that successful online learning communities engage learners and enhance learner identities but the existence of particular barriers may be detrimental to this process, and raised three key questions for this study:

- What elements of online participation in a large forum enhance learner identity, both integrating the learners into the community and concomitantly enhancing their learner identity and sense of agency?

- Do student to student interactions enhance learner identity or do they have lower perceived value in terms of creating feelings of inclusion in the community of practice?

- What value is there in taking community integration from an identity perspective in the study of large online forums?

\section{Method}

This case study, based at The Open University UK, focuses on a student forum based on a single Level 2 module upon which 2,800 students were registered. The module is a compulsory component within a BSc (Hons) degree and focuses on elements of basic developmental psychology. At the time of the study $50 \%$ of the students who registered on the module had already completed one or other of the compulsory Level 2 modules. However for a significant proportion of students (20\%), this module constituted their first experience of Open University study.

The forum itself is one of a number available to students; whilst undertaking the module students have access to a number of forums: The closed course conference comprises a Main Module Forum and separate forums for each assignment and the exam. Additionally there is a student run and moderated forum which is more often used between presentations. The purpose of the forum is peer support during the module study. A single moderator is available to make sure that guidelines are followed and a code of conduct is adhered to. 


\section{Sample}

In order to benefit from ease of access and the remote geographical dispersion of students, the survey was hosted online (Hewson, 2003). It has been argued that this form of data collection can provide more candid information than that provided in other forms of data collection, particularly when used within the context of tutor student research (Johnson, 2001). The online survey aimed to target all students registered on the module; this includes those who rarely or never post as well as those who regularly post or those who use the facility in a read only capacity. More commonly termed Iurkers' the rate of these has been found to be variable, but current research estimates that as many as 45 and $99 \%$ of the population of an online forum may fall into this category, making it essential that their thoughts are sought and represented in the final analysis (Preece, Nonnecke, \&Andrews, 2004).

The final sample consisted of 1,000 randomly selected students (177 male and 823 female) from across two cohorts of the chosen module and final responses were gained from 100 students. The sample was selected by the University Student Research Panel and university codes of ethics were applied. All participants signed an ethics statement outlining the use of data and research protocols.

The particular challenges of tutors carrying out research with students is well documented in the literature (Groundwater-Smith, 1998; Reason \& Bradbury, 2001), raising issues not only in terms of partiality, but also in terms of the degree of candour within this type of investigation. The research within this project was carried out by the forum moderator, herself a tutor on this particular module. In light of this and in light of research evidence which demonstrates that tutor/student research involves this element (Sikes \& Potts, 2008), we recognise that some of the responses may have been influenced by this relationship. However whilst the sample was named, the responses were given anonymously.

\section{Mode of Analysis}

The results were downloaded and quantitatively analysed according to the following questions:

Why do students use online forums?

What is the most common use for this type of forum?

What were self-reported student confidence levels when using online forums?

Qualitative responses to the survey were then analysed using the framework for community identity integration adapted from Baxter (2012a) and illustrated in Figure 3. This framework draws on four elements of online community integration as the students move from a peripheral role within the community (either as lurkers, or as occasional contributors) to a fuller role in which they make regular posts and engage 
more fully with the postings of others. In order to consider student identity within this context the framework draws upon the elements of community engagement outlined in Figure 1, dividing them into four thematic areas: social engagement, academic integration, engagement with peers, and, finally, management and structure of the forum. These areas are further sub-divided into components of each area identified during textual analysis of the qualitative data.

The results are discussed in the section which follows.

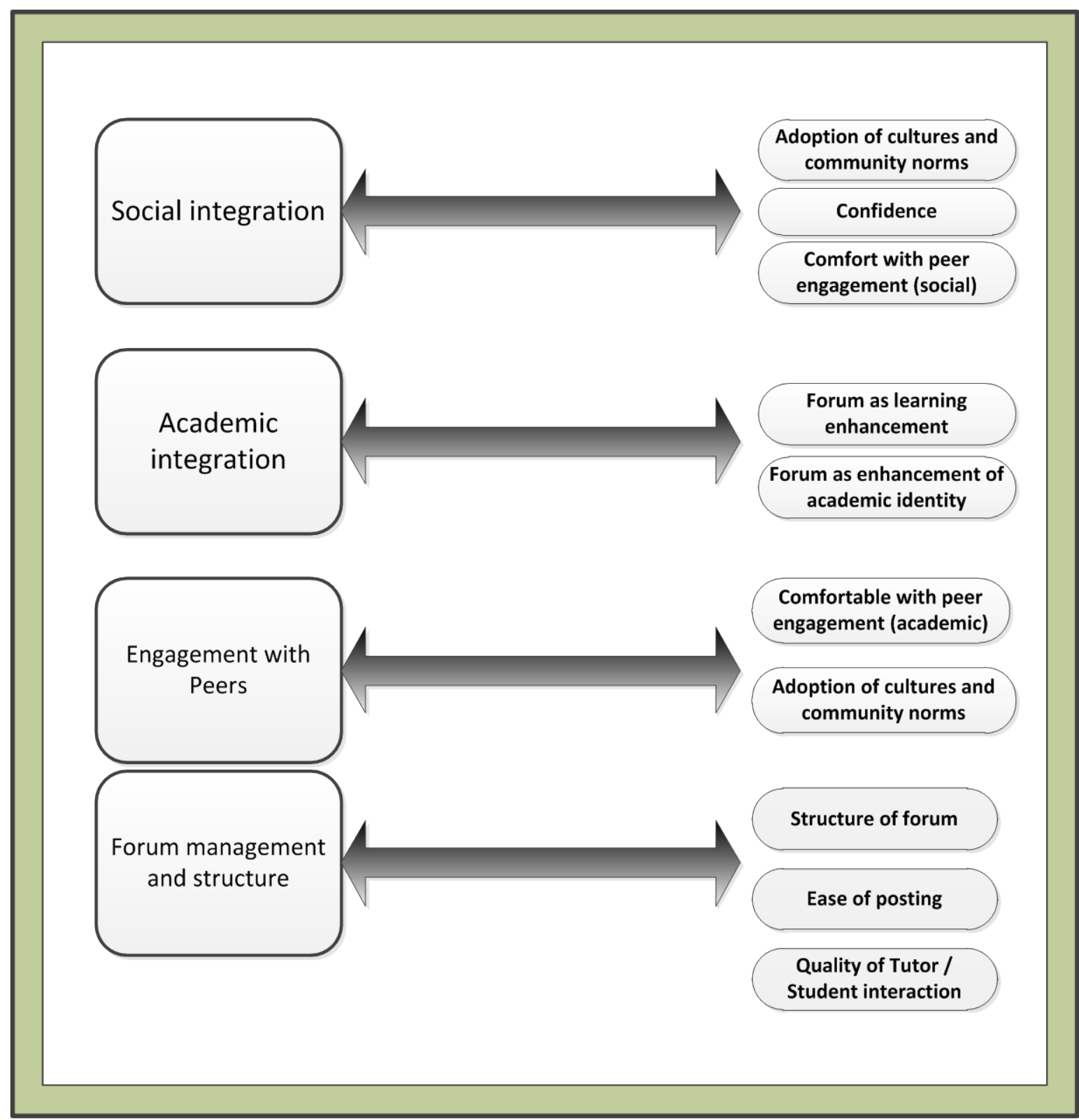

Figure 3. Elements of data analysis. 


\section{Findings}

\section{Quantitative Findings}
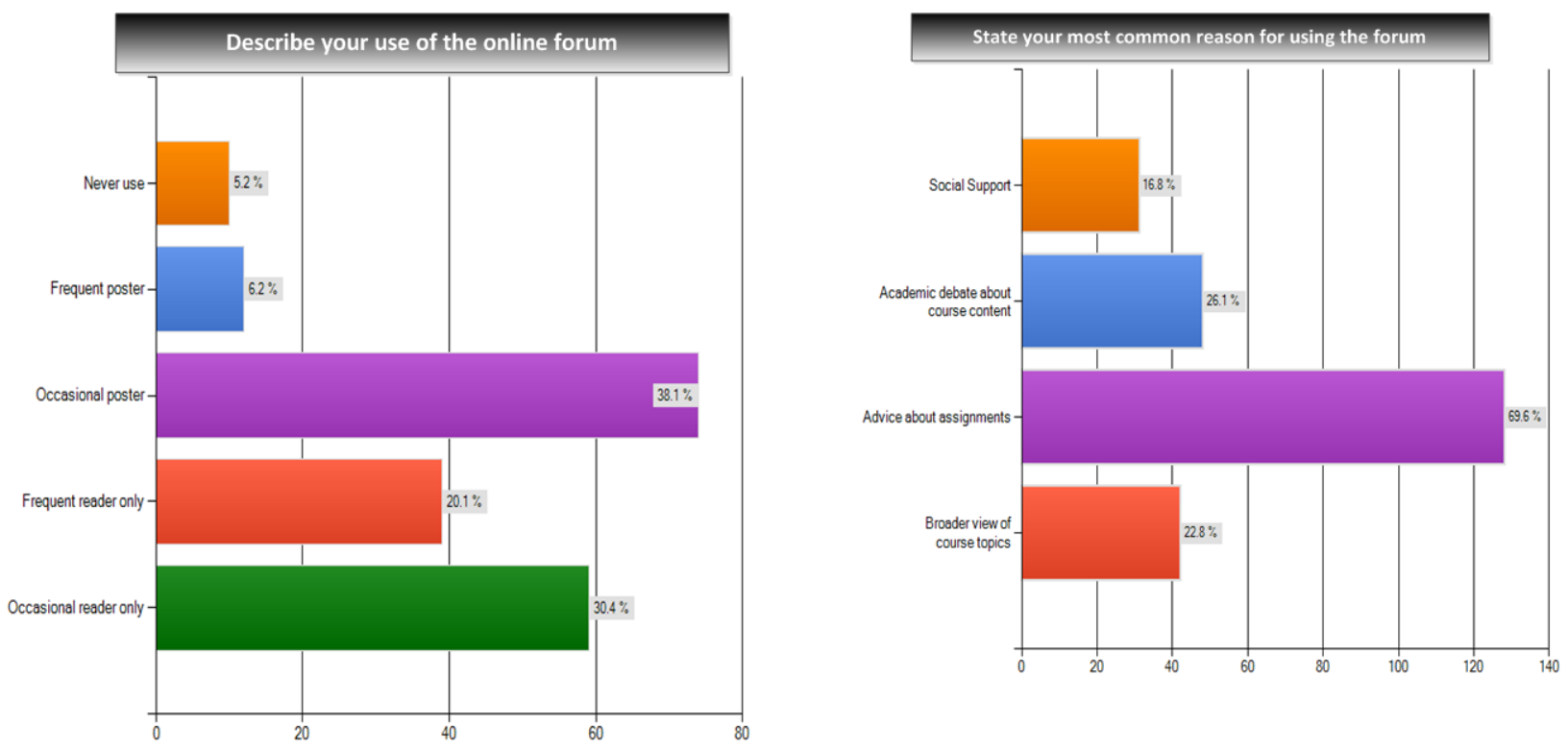

Figure 4. Use of online forums.

Responses to the two questions in Figure 4 (percentages reflect the fact that students were allowed multiple responses for each question ) revealed that most students (38.1\%) participated as occasional posters, whilst those who classed themselves as frequent posters only accounted for $6.2 \%$ of the sample; these students read the forum posts as well as posting. A substantial proportion of the students (20.1\%) stated that they frequently read posts only, whilst $30.4 \%$ stated that they only occasionally read posts. Students in both reader categories did not post on the forum. A small proportion of the sample replied that they never use the forum (5.5\%). In terms of forum use, most students reported that they most frequently used the form for advice about assignments (69.6\%), whilst there were less students that used the forum for academic debate about course content; this, combined with those who used the forum for a broader view of course topics, added up to a significant $48.9 \%$ of students who used the forum as a way in which to integrate with the academic element of the community. 


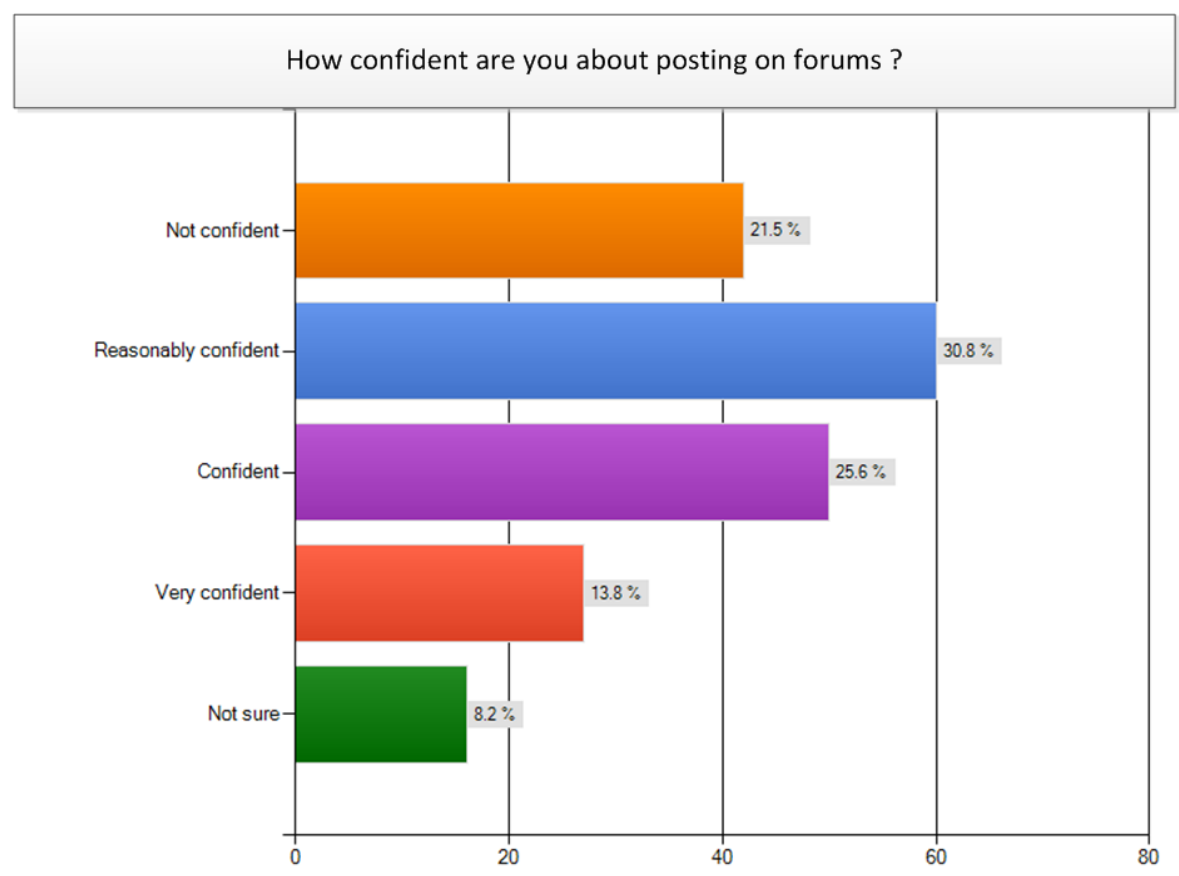

Figure 5. Confidence levels in forum posting.

In terms of their confidence in using the forum, just over 30\% described themselves as reasonably confident and a total of $70 \%$ as either reasonably confident, confident, or very confident; surprisingly only $21 \%$ admit to lacking confidence while posting. Although these results are somewhat surprising given the low number of students that post regularly, they do not indicate whether students like or dislike posting on the forum, or whether in spite of feeling confident they have the time or inclination to regularly read and post on the site. In order to further explore the quantitative information we continue our analysis by examining the qualitative comments that emanated from the survey, analysing them in relation to the framework in Figure 3.

\section{Qualitative Findings}

Whilst the quantitative element of the study uncovered some interesting insights into confidence levels and use of forums, the qualitative findings revealed insights into the issues around using forums and the ways in which the students felt about engagement with both their peers and the forum moderator. These areas are discussed in terms of the three areas outlined in Figure 3.

\section{Social integration.}

In terms of individuals' social integration as discussed, the quantitative information seemed to indicate that students were feeling confident about posting on the forum. This would tend to indicate that levels of social integration were fairly high. But on 
closer investigation the qualitative data revealed that in terms of the three analytical categories within this section, students were experiencing problems with both social peer engagement and adoption of forum cultures and community norms. For one student, the fact that the forum seemed to mix social and academic issues made him extremely uncomfortable: "the wider forums drive me to drink ! I would have more confidence in posting if the forums were more TMA or course info restricted" (P1).

Another was torn between a need for the forum as a support system and a dislike of the ways in which other students behaved online: "I think they are a good support system but I have seen them where people argue and it's upset other students which hasn't been very nice! But I like the fact you can discuss everything and anything on there" (F2).

Concerns with the personal nature of the forums was voiced in terms of both the public nature of their posts and also worries about the security of their data; as one student articulated, "I don't feel my data is protected" (F4).

Worries also centred on what others would feel about their postings and what this would mean for their online identity: "I am really worried about what others will think about my posting" (F5).

One student felt that there should be some firm guidelines on the differences between posting to this type of forum and other purely social forums such as Facebook:

Stuff that you might put on something like Facebook where you are interacting with friends who want to know how well you are doing, they are not always encouraging to other students who may be struggling. I have seen many instances of this where virtual arguments have broken out. (F12)

But there were also some very strong indications that past experience, not only of university forums but of online chat rooms generally, contributed strongly to students' ability to both create online presence and confidence to post: "Having a go and using online chat-rooms, [gives me confidence to contribute] (F14).

The insights into the social element of integration into the community of practice are important in terms of the ability to learn in the social context of real world problems, identified by Etienne Wenger as being core to a community of practice (1998). However there appears to be an assumption by students that the social elements of interaction within this community can give rise to dissent amongst users and impact negatively on both online confidence and presence. Research into the use of online social networking sites, such as the study undertaken by Ellison and colleagues in 2007, revealed that use of Facebook was linked with feelings of psychological well-being, 'Suggesting that it might provide greater benefits for users experiencing low self-esteem and low life satisfaction' (Ellison, Steinfield, \& Lampe, 2007, p. 1143). If this is the case then 
students may well post on a forum in anticipation of receiving the same type of positive reinforcement for their efforts, which is often experienced when posting to other social networking sites. It could be argued that this is part of the creation of a community of practice; that the social elements are inseparable from academic content and that this mirrors a real life approach to dealing with issues within a community, forming an integral part of the move from peripheral to full participation. But the perceptions of a number of students reflect that because the forum is hosted by an academic community that the focus should be on academic debate.

The data support the idea of the need to create online social presence, and the strong links between this and positive and negative emotions (Angelaki \& Mavroidis, 2013), and the concerns voiced by student F5, reflect the deep concerns around the ways in which postings reflect the online persona of individuals. This is reflected in a number of responses during the study, for example the statement made by F124, relating to anonymity below. But insights into what enables students to post with confidence revealed the use of other online media to be strongly influential in their ability to create online presence and concomitant online resilience and motivation to post, as this student reported: "I think I'm of the Facebook generation, whereby posting on forums is a widely used form of communication, so I've had a lot of practice in it" (F69). Although some students clearly felt that the forums were not an appropriate arena for social engagement, when this social engagement was specifically linked to academic engagement their accounts were substantially different.

\section{Academic integration and engagement with peers.}

As discussed earlier, some research reflects that student to student interaction has less perceived value than that between tutor and student (Loizidou-Hatzitheodoulou, Vasala, Kakouris, Mavroidis, \& Tassios, 2001); although this element did appear within the data it predominantly manifested in frustrations around social use of the forum. The data did reflect that students felt a sense of responsibility in terms of their posts; and that this responsibility was articulated in the degree to which they felt confident in their knowledge of the subject. Where this was lacking, students tended to perceive their own role as being fairly peripheral to the academic community:

I don't think my lack of confidence in forums is down to the university. I am much more of a reader than a contributor: a last minute student so someone has always asked my question. Also some students seem so academically advanced I feel my contribution may be stupid. (F6)

Another student felt that the forum was too public and that one would be publically shamed by asking a question founded on a fundamental misunderstanding: "If one could have the choice of writing anonymously it may be easier, as I personally would be 
a bit embarrassed if I really did misread the question, as basically the whole forum would know about it" (F124).

Although it is not clear whether this individual was participating as a lurker, reading posts rather than posting, the post suggests that they had little sense of the forum as a community, seeing it rather as a FAQ element in terms of the course, and certainly not as a learning environment. This may suggest that there is value in addressing the metacognitive functions of the forum and of exploring to a greater extent the student understandings of how they learn online, reflecting Akyol and Garrison's argument that this element is fundamental to successful online engagement (2011). What is not clear is the extent to which this contributes to learner identity. It also raises questions about the identity and role of the lurker within the community. Often pejoratively labelled a nonparticipator, or in corporate forums 'the taker who doesn't give back' (Smith \& Kollock, 1999, p. 44), the lurker identity is an interesting one in terms of his or her role identity within the online community. The work of Nonnecke and Preece has uncovered some interesting insights into the way in which lurkers both perceive their own role in relation to the online community and are in turn imagined by other community members (Nonnecke, Andrews, \& Preece, 2006; Preece, Nonnecke, \& Andrews, 2004). The statements made by F6 and F124, above, reflect some of the findings of Nonnecke and Preece in the way in which learners imagine their online role, exemplifying the ways in which online learners perceive a reading only role and the qualities that they ascribe to colleagues that do post.

Many of the respondents in their research stated that by not posting they were contributing to the well-being of the community, citing the virtues of being a good listener, of not dominating and only posting if they feel that their post would offer a perceptibly valuable contribution to the community (Nonnecke, Andrews, \& Preece, 2006, p. 212). One of the most interesting insights to emerge from their research in relation to this study was that individuals felt that by posting they were assuming a degree of expertise in the subject: In these instances even an opinion, due to its text based nature (rather than spoken), assumed an air of authority (p. 212). If this is the case then posting to some individuals may seem like too precipitate a move from novice to expert within the online community: an element worthy of further investigation.

This along with a number of comments on the way participants engaged with academic elements of the forum supported the findings of Ardichvili, Page, and Wentling (2003) and reflected that the affective domain is very influential in terms of enhancement of student engagement and identity, whilst also supporting its role in the construction of social presence, of an online identity that positively affected learner agency and motivation (Angelaki \& Mavroidis, 2013) as this student articulates: "I am not afraid to speak up in the forums as I believe we can learn from our mistakes" (F61).

In the case of this student (and a number of others), there was a substantial amount of evidence that developing online presence in other social networking situations proved very helpful in encouraging swifter engagement with this forum, and that this not only 
contributed to a deeper level of participation but also led to peer facilitation, students helping less confident students to participate: "Most posts seem friendly and nonjudgemental. There is an atmosphere of helpfulness and of all being in the same boat" (F67).

But there was also evidence that failure to achieve adequate social online presence was problematic, not only for the individual but for those attempting to engage with that particular individual: "My main problem is understanding how the forums are used by others, you know: information about other users" (F50).

Feelings of posting into a vacuum with textual identities feeling indistinct and lacking substance caused some learners to feel isolated, either because this element made them feel reluctant to post, or because they felt that because they didn't feel any sense of familiarity with other participants, they found it difficult to feel part of the forum.

Feelings of academic integration and concomitant periphality appeared to be more influenced by student's ability to appear knowledgeable and confident online: the extent to which their online identity manifested as peripheral or central to the academic community. This was achieved in a number of ways : via integration on the part of other students who encouraged participation by peer support; by familiarity with the construction and maintenance of an online identity due to previous participation in social networking sites; and finally through the extent to which learners could adapt to the culture of the forum or perceived it to be an alien and sometimes hostile environment. The extent to which students were able to engage with peers in a supportive and helping manner appeared to colour their perceptions of the community, enhancing their sense of legitimacy and authenticity. This would tend to indicate that further studies such as that carried out by Hew and Cheung in 2008 into peer facilitation may be helpful in evaluating the extent to which peer facilitation schemes could enhance online presence and promote salient and agentive online student identities.

The final area for data analysis investigates forum management and structure and the impact of moderator interventions and activities.

\section{Forum management and structure.}

Although the previous discussions reflect the plentiful evidence in support of Zembylas' argument that familiarity with online forum participation aids swifter integration, and also that students were in some cases employing online communication styles learned elsewhere, there was also evidence to suggest that students viewed this large forum as being very different both in nature and structure to other online environments. The actual structure of the forum was often seen to be problematic with sheer quantity of posts proving overwhelming to some students: "Sometimes it seems confusing when trying to find a particular topic as some topics seem to be merged and some do not" (F96). 
A substantial element of whether the forum was perceived to be useful was based around perceptions of the role of the moderator. In terms of integration into the community the students mentioned less about the expert role of the moderator, and spoke more of the moderator in terms of an ability to manage. This was particularly so in terms of the management of difficult situations, often termed 'flaming' in the online environment: "Sometimes I've seen some very negative responses to well-meaning posts and would like to see these removed" (F105).

Although the moderator in this case was not taking a tutoring role there was a feeling amongst a number of students that this should be the case, that the moderator should both initiate and shape discussions: "In other forums I found directed discussions and small buddy groups used there very useful, this could be extended here and make this much more than a social forum" (F19).

The feeling that the moderator should be acting in the role of academic expert offers some insight into the ways in which learners need the moderator in order to define their own positions within the community. Without the expert taking a strong steer and providing shape for discussions, there seemed to be a sense amongst students that the community had no shape, that it lacked an aspirational centre to which the students could gravitate in their progress from novice to expert. This appeared to impact on student perceptions of usefulness of the forums and core beliefs about the purpose of a forum in this academic context. There was the feeling among some students that this social forum was out of place in an academic context and that remarks not pertaining directly to academic matters should be reserved for Facebook pages or other sub-group formations outside of the control of the university.

Work done by Mazzonlini and Maddison (2003) reflects how difficult it is for moderators to achieve a balance between too much intervention and too little, whilst also highlighting how perceptually important for students it is to achieve this balance.

\section{Conclusion}

The study has revealed that the insights gained from taking this approach to the study of large forums has value in its capacity to reveal learner perceptions and the ways in which they impact on motivation and learner identity. In exploring the elements which enhance student motivation within this environment, the research has highlighted both the power and complexity of using this medium in order to create an online academic student community of practice. Many of the elements which the literature points to as enhancing student motivation and swift integration within the forum are paradoxically the very attributes that may prove detrimental to the participation and integration of other students. A particularly powerful example of this is the transfer of skills and expectations acquired within the context of other social networking environments to the academic environment. 
The research also illuminates both challenge and opportunities within the context of student to student interaction. Although students found some student to student interactions problematic there was no evidence that those containing academic content were viewed as having a lower perceptible value than tutor to student interactions. However what was evident was that social interactions were viewed as having lower value than those which related to academic content. This suggests that perhaps the nature of this forum may need to be reviewed in light of student expectations. An important finding of this study is that academic peer to peer support was both valued and valuable in its capacity to place academic issues in the affective as well as the cognitive domain, supporting the work of Loizidou-Hatzitheodoulou et al. (2001). In terms of the function of this type of forum as an identity enhancer, its function to encourage students to feel part of an academic community, these insights are important.

The work highlighted a number of elements pertaining to the challenges inherent in using this forum for academic community integration and points to some elements that are worthy of consideration in pedagogic terms. Returning to the analytic framework illustrated in Figure 3 the investigation raises several considerations for future research. In terms of forum management and structure, the study has highlighted the power of student expectations in this realm. With little understanding of the constructivist premise upon which this tool is based, students appear to struggle with their understandings of what the forum is for, what purpose it serves in terms of their overall academic goals and aspirations. It was clear to most that this forum was designed as a form of support, but this term in itself needs to be unpacked. Evidence of this was most prevalent in the ways in which students were attempting not only to adapt presence creation techniques learned elsewhere, but also within their expectations of what support means in this context, powerfully illustrated by the student who articulated feelings that some students were expecting similar reactions from online peers in this context, to the positive reinforcement they receive on Facebook when making similar postings.

Expectations of the tutor were voiced in terms of the way in which the forum is managed and this area again raised the difficulties outlined by Mazzolini and colleagues in terms of levels of actual and anticipated tutor intervention (2003). Although there was evidence that students were aware of the tutor as an authority figure, reactions to this were mixed, some students feeling that this constrained expression, and others feeling that the tutor needed to take a more assertive stance, particularly in relation to posts that were perceived to be inappropriate in some form. In terms of student integration into the community, this was described on a number of occasions as 'policing', and perceived by a number of students as a vital element in order to feel able to safely contribute to the forum. This element of psychological safety, initially featuring in the work of Maslow (Maslow, Frager, \& Fadiman, 1970; Maslow \& Lowry, 1968), was later adapted by Gilly Salmon as a central tenet within her work in relating Maslow's hierarchy of needs to the online moderating context (see Salmon, 2002; Salmon, 1998). 
Finally the study revealed that whilst there are potentialities within this type of interaction that these need to be evaluated in terms of the detrimental impact that large forums of this kind may have on learner engagement and identity. Early studies into MOOCs carried out at The University of California indicate that this form of learning, to which large online forums are central, does appear to have high levels of attrition (Rivard, 2013). Recent work carried out at The Open University UK reflects that the average completion rate (completing a course and receiving a certificate of completion) is 10\% (Parr, 2013; Jordan, 2013). Although there are a number of confounding variables within these studies, they do raise several questions relating to their value in terms of creating learner identity and the sense that this learner identity is rooted in a community of academic practice which both creates and sustains it through periods of difficulty and doubt. If learner identity and feelings of community integration are central to learner motivation as a number of studies have indicated they are, then the consideration of both elements may be vital to the future of online learning. 


\section{References}

Akyol, Z., \&Garrison, D. R. (2011). Assessing metacognition in an online community of inquiry. The Internet and Higher Education, 14(3), 183-190.

Anderson, T., \& McGreal, R. (2012). Disruptive pedagogies and technologies in universities. Educational Technology and Society, 15(4), 380-389.

Angelaki, C., \& Mavroidis, I. (2013). Communication and social presence: The impact on adult learners' emotions in distance learning. European J ournal of Open, Distance and e-Learning, 16(1), 78.

Ardichvili, A., Page, V., \&Wentling, T. (2003). Motivation and barriers to participation in virtual knowledge-sharing communities of practice. J ournal of knowledge Management, 7(1), 64-77.

Baxter, J . (2010). Bien dans sa Peau : An investigation into the role of professional learning on the online teaching identities of HE lecturers. 21 Century Academic Identities Conference. Retrieved from http:// oro.open.ac.uk/26313/

Baxter, J . (2011). An investigation into the role of professional learning on the online teaching identities of higher education lecturers. CREet : The Faculty of Education and Language Studies. Retrieved from http:// oro.open.ac.uk/33928/

Baxter, J . (2011a). Public sector professional identities: Etiolation or evolution; a review of the literature. Retrieved from http:// oro.open.ac.uk/ 29793/

Baxter, J . (2012). The impact of professional learning on the online teaching identities of higher education lecturers: The role of resistance discourse. European J ournal of Open, Distance and E-Learning, 1(2).

Baxter, J . (2012a). Who am I and what keeps me going? Profiling the distance student. International Review of Research in Open and Distance Learning, 13(4).

Baxter, J ., \& Martyn, R. (2010). Student progression: Effective interventions and areas for development. The Open University, UK.

Burke, P. J ., \& Reitzes, D. C. (1981). The link between identity and role performance. Social Psychology Quarterly, 83-92.

Caravallo J ohnson, G., \&Watson, G. (2004). Oh Gawd, How am I going to fit into this?': Producing mature first year student identity. Language and Education, 18(6), 474-486.

Cleveland-Innes, M., \& Campbell, P. (2012). Emotional presence, learning, and the online learning environment. The International Review of Research in Open and Distance Learning, 13(4), 269-292. 
DeSanctis, G., Fayard, A.-L., Roach, M., \&J iang, L. (2003). Learning in online forums. European Management J ournal, 21(5), 565-577.

Duemer, L., Fontenot, D., Gumfory, K., Kallus, M., Larsen, J . A., Schafer, S., \&Shaw, B. (2002). The use of online synchronous discussion groups to enhance community formation and professional identity development. The J ournal of Interactive Online Learning, 1(2), 1-12.

Ellison, N. B., Steinfield, C., \&Lampe, C. (2007). The benefits of Facebook "friends:" Social capital and college students' use of online social network sites. J ournal of Computer-Mediated Communication, 12(4), 1143-1168.

Garrison, D. (2007). Online community of inquiry review: Social, cognitive, and teaching presence issues. J ournal of Asynchronous Learning Networks, 11(1), 61-72.

Garrison, D. R., \& Cleveland-Innes, M. (2005). Facilitating cognitive presence in online learning: Interaction is not enough. The American J ournal of Distance Education, 19(3), 133-148.

Groundwater-Smith, S. (1998). Putting teacher professional judgement to work. Educational Action Research, 6(1), 21-37. doi: 10.1080/09650799800200051

Hammond, M. (2000). Communication within on-line forums: The opportunities, the constraints and the value of a communicative approach. Computers \& Education, 35(4), 251-262.

Haycock, J . (2008). Making first class impressions. Paper presented at the 3rd Open CETL Conference: Building Bridges, The Open University UK.

Henri, F. (1992). Computer conferencing and content analysis. Collaborativelearning through computer conferencing (pp. 117-136). Springer.

Hew, K. F., \& Cheung, W. S. (2008). Attracting student participation in asynchronous online discussions: A case study of peer facilitation. Computers \& Education, 51(3), 1111-1124.

Hewitt, A., \& Forte, A. (2006). Crossing boundaries: Identity management and student/ faculty relationships on the Facebook. Poster presented at CSCW, Banff, Alberta, 1-2.

Hewson, C. (2003). Conducting research on the internet. The Psychologist, 16(6), 290293.

J ohnson, C. M. (2001). A survey of current research on online communities of practice. The Internet and Higher Education, 4(1), 45-60. 
J onassen, D., Davidson, M., Collins, M., Campbell, J ., \&Haag, B. B. (1995).

Constructivism and computer mediated communication in distance education. American J ournal of Distance Education, 9(2), 7-26.

J ordan, K. (2013). MOOC Completion rates: The data. Retrieved from http:// www.katyjordan.com/MOOCproject.html

Lave, J ., \&Wenger, E. (1991). Situated Learning: Legitimate periperal participation. Cambridge Cambridge University Press.

Loizidou-Hatzitheodoulou, P., Vasala, P., Kakouris, A., Mavroidis, I., \&Tassios, T. (2001). Types of communication in distance learning and their contribution to the educational process. The case of the students of the postgraduate module 'Open and Distance Education' of HOU. Paper presented at the 1st Panhellenic Conference for Open and Distance Education , Greece.

Maslow, A. H., Frager, R., \& Fadiman, J . (1970). Motivation and personality (Vol. 2). Harper \& Row New York.

Maslow, A. H., \&Lowry, R. (1968). Toward a psychology of being. London: Wilder Publications.

Mazzolini, M., \& Maddison, S. (2003). Sage, guide or ghost? The effect of instructor intervention on student participation in online discussion forums. Computers \& Education, 40(3), 237-253.

Nonnecke, B., Andrews, D., \& Preece, J . (2006). Non-public and public online community participation: Needs, attitudes and behavior. Electronic Commerce Research, 6(1), 7-20.

OLTF. (2011). Collaborate to compete: Seizing the opportunity of online learning for UK higher education. In D. L. Bridley (Ed.), HEFCE: The Higher Education Funding Council for England.

Parr, C. (2013). MOOC completion rates below 7\%. The Times Higher Education. Retrieved from http:// www.timeshighereducation.co.uk/ news/mooccompletion-rates-below-7/2003710.article

Preece, J ., Nonnecke, B., \&Andrews, D. (2004). The top five reasons for lurking: Improving community experiences for everyone. Computers in Human Behavior, 20(2), 201-223.

Reason, P., \& Bradbury, H. (2001). Handbook of action research: Participative inquiry and practice. London: Sage Publications Limited. 
Rivard, R. (2013). Measuring the MOOC dropout rate. Retrieved from http:// www.insidehighered.com/news/ 2013/03/08/ researchers-explore-whotaking-moocs-and-why-so-many-drop-out

Salmon, G. (2002). Moderating: The key to teaching and learning online. London: Routledge.

Salmon, G. K. (1998). Developing learning through effective online moderation. Active Learning, 9 December, 3-8.

Shea, P., \& Bidjerano, T. (2009). Community of inquiry as a theoretical framework to foster "epistemic engagement" and "cognitive presence" in online education. Computers \&Education, 52(3), 543-553.

Sikes, P., \& Potts, A. (2008). Researching education from the inside: Investigations from within. London: Routledge.

Smith, M. A., \& Kollock, P. (1999). Communities in cyberspace. London: Psychology Press.

Thomas, M. J . (2002). Learning within incoherent structures: The space of online discussion forums. J ournal of Computer Assisted Learning, 18(3), 351-366.

Wenger, E. (1998). Communities of practice: Learning meaning and identity. New York: Cambridge University Press.

Xie, K., DeBacker, T. K., \& Ferguson, C. (2006). Extending the traditional classroom through online discussion: The role of student motivation. J ournal of Educational Computing Research, 34(1), 67-89.

\section{Athabasca University $\mathbf{I}$}

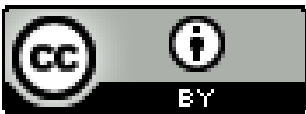

